\title{
Envejecimiento demográfico y exclusión social en barrios obreros degradados de Las Palmas de Gran Canaria
}

\section{Demographic aging and social exclusion in Las Palmas de Gran Canaria degraded worker-class districts ${ }^{1 *}$}

\author{
Jordi Boldú Hernández $z^{2}$ y Josefina Domínguez-Mujica ${ }^{3}$
}

\begin{abstract}
RESUMEN
El objeto de estudio de este artículo lo constituye la caracterización de la vulnerabilidad urbana de dos barrios obreros de Las Palmas de Gran Canaria: San Nicolás y La Isleta. El ciclo de vida de dichos barrios y el de sus vecinos corren paralelamente, de forma que el envejecimiento de sus poblaciones y de su tejido habitacional se muestra como un signo de obsolescencia y de atonía urbana y demográfica en la capital de Gran Canaria (España). Para definir el estado actual de vulnerabilidad que los afecta, en esta investigación se utilizan técnicas cuantitativas y cualitativas de análisis. Las primeras permiten el estudio sociodemográfico (Censo de Población y del Padrón) y de su tejido habitacional y urbano (Censo de Viviendas y Catastro); las segundas (entrevistas y grupos de discusión) ofrecen el testimonio de sus residentes en relación con su sentimiento de pertenencia a dichos barrios. Los resultados de la investigación desarrollada muestran el interés de la gerontología ambiental, a nivel de microescala, para diagnosticar situaciones que requieren un tratamiento diferenciado en ámbitos urbanos, con la intención de paliar la vulnerabilidad y contribuir a la construcción de ciudades más justas desde un punto de vista social y espacial.
\end{abstract}

1 * Este artículo se ha realizado en el marco del Proyecto de Investigación I+D+i titulado «Crisis y vulnerabilidad en ciudades insulares españolas. Transformaciones en los espacios de reproducción social», financiado por el Ministerio de Economía y Competitividad (2016-2018) (Fondos FEDER).

2 Universidad de Las Palmas de Gran Canaria bolduhernandez@gmail.com ORCID iD: https://orcid.org/0000-0003-1456-4600

3 Universidad de Las Palmas de Gran Canaria josefina.dominguezmujica@ulpgc.es ORCID iD: https://orcid.org/0000-0001-7460-5553

Copyright: (C) 2018 CSIC. Este es un artículo de acceso abierto distribuido bajo los términos de la licencia de uso y distribución Creative Commons Reconocimiento 4.0 Internacional (CC BY 4.0). 
Palabras Clave: vulnerabilidad urbana; gerontología ambiental; ciclo de vida; envejecimiento demográfico; barrios obreros; Las Palmas de Gran Canaria.

\begin{abstract}
The aim of this article is the characterization of the urban vulnerability of two workerclass districts in Las Palmas de Gran Canaria: San Nicolás y La Isleta. The lifecycle of these districts and of their neighbors parallel run, so the aging of their population and of housing fabric is shown as an obvious sign of obsolescence and urban and demographic atony in the main city of Gran Canaria (Spain). To determine the current level of their vulnerability quantitative and qualitative methods are used in this research. The first of them allow the sociodemographic study (Census of Population and Continuous Census) and of the housing and urban fabric (Census of Housing and Cadaster); the second (interviews and discussion groups) offer the statements of their neighbors with regard to their feelings of belonging to those districts. The results of the research developed exhibit the interest of environmental gerontology at a microscale level, to diagnose situations that require differentiated treatment in urban areas, contributing to palliate the vulnerability and to construct fairer cities from a social and spatial point of view.
\end{abstract}

KEY WORDS: urban vulnerability; environmental gerontology; life cycle; demographic aging; lower-class district; Las Palmas de Gran Canaria.

Cómo citar este artículo / Citation: Boldú Hernández, J. y Domínguez-Mujica, J. (2018): "Envejecimiento demográfico y exclusión social en barrios obreros degradados de Las Palmas de Gran Canaria”, Estudios Geográficos, LXXIX/285, pp. 469-500. https://doi.org/10.3989/estgeogr.201818.

\title{
INTRODUCCIÓN
}

Muchos autores definen la ciudad postindustrial como aquélla en la que han ganado protagonismo las funciones terciarias y las clases medias. Desde esta perspectiva se han analizado las transformaciones que la caracterizan y los procesos sociales que las acompañan, como consecuencia del aumento de la competencia, el cambio tecnológico, la integración económica y la globalización de los mercados (Vázquez-Barquero, 1999). Sin embargo, a nivel intraurbano, son infrecuentes los estudios acerca de los barrios con escasa centralidad, aquejados por problemas de obsolescencia, en los que se dan ciertas dinámicas socio-demográficas que han paralizado el tiempo, definiendo las llamadas áreas del envejecimiento vulnerable (Sánchez-González, 2009); espacios medioambientales más pobres, con población envejecida que, como han señalado Andrews y Phillips (2005), han sido relegados en términos 
de investigación y ponen de manifiesto las dimensiones estructurales de la vulnerabilidad, una construcción social generada a partir de desigualdades sociales, falta de oportunidades de empoderamiento y de acceso a la protección social (Sánchez-González y Egea Jiménez, 2011).

Estos barrios, que se han mantenido ajenos a la inmigración y a las dinámicas de sustitución o revitalización social, en los que predomina una población con menor poder adquisitivo, han visto cómo el envejecimiento los hace languidecer, a la vez que se deterioran los inmuebles y que el paso de los años pesa, condicionando su futuro. Esta situación revierte, en algunos casos, gracias a una mayor cohesión social, siendo el propio vecindario el que dinamiza la comunidad y contribuye a mantener más activo el barrio o a consecuencia de procesos de desarrollo económico.

En España, en los ámbitos urbanos, el proceso de envejecimiento demográfico ha sido ineluctable, no lo han frenado las tendencias propias de la ciudad postindustrial y tampoco se ha visto condicionado de forma definitiva por la crisis económica, — si acaso esta lo ha acentuado, con la contracción de la inmigración. Por tanto, se trata de un proceso latente y de largo alcance, que no solo afecta a los centros históricos, sino que se ha impuesto como una realidad más compleja en aquellos barrios obreros de la primera industrialización, que se han mantenido ajenos a los procesos de gentrificación, donde es necesario reconocer la interacción entre los ciclos de vida de los propios barrios y de sus habitantes. Dos de estos, en los que se aprecia la intensidad del envejecimiento, son los de San Nicolás y La Isleta en Las Palmas de Gran Canaria. Dichos barrios se localizan en un ámbito urbano que podríamos calificar como de in-betweenness, en la primera periferia de Las Palmas de Gran Canaria, la de la expansión obrera de las últimas décadas del siglo XIX y principios del XX.

El objetivo de la investigación desarrollada es el de analizar este proceso de envejecimiento demográfico que los caracteriza y definir las claves que nos permiten interpretar el deterioro socioeconómico y urbano que lo acompaña. Ahora bien, el estudio detallado de ambos espacios pone de manifiesto reacciones y resistencias que definen dos modelos distintos. El peso de la historia, común a ambos hasta los años del desarrollismo, se ve modelado en la fase de la ciudad postindustrial, en el caso de La Isleta, por los efectos inducidos que supone el desarrollo turístico de un área próxima, la de la playa de Las Canteras, así como por los proyectos de renovación urbana acometidos. A ello se suma una mayor conciencia e identidad de barrio, todo lo cual minimiza el impacto del envejecimiento y hace aflorar un sentido comunitario, con reacciones propias del llamado envejecimiento activo, que refuerzan la relación entre medioambiente e identidad en las personas de 
edades avanzadas y que tanta repercusión han alcanzado en los estudios de gerontología ambiental (Rowles y Chaudhury, 2005; Rowles y Bernard, 2013) o como se han denominado más recientemente, de gerontología geográfica (Skinner, Andrews y Cutchin, 2018). Frente a este modelo, San Nicolás ofrece un panorama mucho más desalentador. La atonía demográfica y el deterioro del tejido urbano, pese a las iniciativas de revitalización desarrolladas, hacen augurar un futuro de declive imparable.

Para cubrir este objetivo, este artículo se estructura de la siguiente forma. Tras esta introducción, en primer lugar, se presenta un estado de la cuestión en el que se hace hincapié en la bibliografía publicada acerca de los procesos de envejecimiento demográfico en áreas urbanas. Un segundo apartado está dedicado a las fuentes y metodología de análisis desarrollados en la investigación. En el tercer capítulo abordamos los ciclos de vida de dichos barrios, con una atención especial a los factores socioeconómicos que han determinado su evolución, así como a sus actuales condiciones de habitabilidad. El cuarto epígrafe trata del proceso de envejecimiento y de las características sociodemográficas y económicas de la población envejecida. En quinto lugar se abordan las dotaciones socio-sanitarias de las áreas de estudio y los problemas de acceso a los servicios por parte de los ancianos. Por último, se analiza el sentimiento de pertenencia e identidad ambiental de los vecinos y su gestión, es decir, el papel de la comunidad frente al envejecimiento. Las conclusiones sintetizan los aspectos más significativos del estudio y las referencias bibliográficas cierran el artículo.

\section{LOS PROCESOS DE ENVEJECIMIENTO EN ÁREAS URBANAS: ESTADO DE LA CUESTIÓN}

El envejecimiento poblacional resulta un fenómeno demográfico del que apenas se comienza a hablar en la segunda mitad del siglo pasado (Bello Sánchez, 2013), si bien, desde esas fechas y, especialmente, desde el cambio de siglo, se suceden las investigaciones sobre los procesos de envejecimiento. Este hecho se ha visto favorecido por la creciente preocupación acerca de las consecuencias que supone el viraje hacia estructuras poblacionales con predominio de personas de edades ancianas y las consecuencias que ello tiene para el ámbito económico, social y cultural.

Como es bien sabido, las causas del envejecimiento actual de la población se remontanal impacto de la revoluciónindustrial, cuando los avances tecnológicos, médicos y de mejora de la calidad de vida propiciaron una disminución notable de la mortalidad extraordinaria y ordinaria. Con todo, las pautas reproductivas seguían manteniéndose inalteradas, aferradas al pensamiento de concebir para 
asegurar la descendencia y la sostenibilidad económica de la familia, como respuesta a los elevados índices de mortalidad infantil. Esta primera etapa de la transición demográfica dio lugar a un crecimiento acelerado de la población y a una estructura demográfica rejuvenecida.

Las transformaciones en el comportamiento moderno de las sociedades, con cambios estructurales en la composición familiar y pautas de nupcialidad y reproducción radicalmente distintas, sumado ello a los acelerados procesos de urbanización, han contribuido a la contracción de unas tasas de natalidad y fecundidad que, actualmente, prosiguen en su descenso o estancadas. A su vez, el aumento de la esperanza de vida ayuda a engrosar el volumen de las cohortes de la población anciana, como consecuencia directa de la reducción de las tasas de mortalidad, generando estructuras demográficas en transición hacia el envejecimiento (Abellán García et al., 1990).

En cuanto a las consecuencias del envejecimiento de la población desde una perspectiva geográfica, se ha abordado más el estudio de los contrastes espaciales en la distribución de las personas mayores, pero no tanto la componente ambiental como factor de vulnerabilidad; este enfoque adquiere relevancia en estudios propios de los paradigmas geográficos de la década de los setenta y sucesivos (Peet y Rowles, 1974). Entonces empezó a cobrar fuerza una nueva área de conocimiento: la gerontología ambiental, que reúne enfoques tan interdisciplinarios como la piscología ambiental, la geografía de la población, la sociología o la geografía urbana, entre otras. El interés por entender las secuelas del envejecimiento en el entorno y cómo mejorar la calidad de vida en la vejez desde la planificación y el urbanismo, fue un acicate para investigadores como Windley (1972) o Lawton (1975).

Desde la premisa de comprender las condiciones de vida de las personas mayores y su relación con el espacio en el que viven, la gerontología ambiental ha demostrado un interés especial en los efectos del envejecimiento demográfico y la urbanización en el desarrollo de las sociedades futuras, integrándose en líneas de investigación más modernas como la vulnerabilidad socio-espacial o urbana, perspectivas adoptadas en los estudios sobre Valparaíso (Fadda y Cortés, 2009), Madrid (Rojo, Fernández-Mayoralas y Pozo, 2000) o La Habana (Bello Sánchez, 2013), por ejemplo. Además, la óptica de la senectud en los estudios de vulnerabilidad urbana adquiere notoriedad al entenderse como escenarios propicios para el análisis de la exclusión social y las fragilidades socio-espaciales (Sánchez-González, 2007, 2009 y 2015; Smith, 2009; Narváez Montoya, 2011; entre otros).

El modelo geográfico que trae consigo el envejecimiento demográfico advierte de una polarización espacial del territorio: por un lado, la residencialización 
dispersa y diseminada de núcleos rurales con predominio de ancianos y, por otro, la concentración urbana de población envejecida. Dentro de las fronteras metropolitanas el fenómeno es más complejo, dado que el impacto de la vulnerabilidad social de los mayores dependerá del contexto urbano en el que se encuentren: por un lado, aquellas áreas más jóvenes y atractivas con menor incidencia de la vulnerabilidad (gentrificación, nuevas promociones, transformaciones urbanas, etc.), frente a otros escenarios de expulsión ajenos a las intervenciones urbanas y que acrecientan su estatus de marginalidad y exclusión social (Sánchez-González, 2007). Por lo tanto, la componente ambiental y el tejido urbano-residencial, con especial atención al estado del barrio y las viviendas, la funcionalidad del espacio público y los sistemas de movilidad y accesos, etc., son algunas de las claves para analizar posibles escenarios de desigualdad, pobreza, dependencia, etc. así como para defender la necesidad de revertir estas situaciones mediante intervenciones inclusivas (Scharf y Keating, 2012; Golant, 2015).

Es por ello que el concepto de escala se convierte en la esencia metodológica de los estudios al respecto, puesto que las consecuencias del envejecimiento demográfico en el espacio son el resultado de problemas de índole macro y microescalar. Por una parte, la macroescala (ciudad, barrio, etc.) otorga una visión de conjunto fundamental, mientras que la microescala (vivienda y hogar) se convierte en una herramienta de trabajo para abordar problemáticas más específicas del espacio habitado (Andrews y Phillips, 2005; Puga González y Abellán García, 2006). Desde esta perspectiva, se ha abierto un campo de estudio afín a la Geografía, que se ha enriquecido con las investigaciones relacionadas con los ciclos de vida, como confirman Wahl, Iwarsson y Oswald (2012: 307), cuando señalan que «la ecología del envejecimiento sitúa a la vejez como una fase crítica del curso de vida, profundamente influenciada por el medio ambiente físico». En consecuencia, aunar los ciclos de vida demográfico y urbano, se convierte en piedra angular de la gerontología ambiental, pues dota a las investigaciones geográficas de compromiso social contra la vulnerabilidad socio-espacial de los mayores (Puga González y Abellán García, 2006; Sánchez-González, 2007) y otorga a los geógrafos un relevante papel en la planificación territorial.

\section{FUENTES Y METODOLOGÍA DE ANÁLISIS}

Para la fundamentación teórica y metodológica de la investigación desarrollada se acometió una revisión bibliográfica en relación con el envejecimiento 
demográfico, la vulnerabilidad urbana, las políticas y acciones de atención social a los ancianos y la metodología de análisis sociodemográfico. Por su parte, el análisis empírico combinó técnicas cuantitativas y cualitativas de investigación, además del reconocimiento de campo. Entre las primeras destacan las de carácter sociodemográfico y urbanístico y, entre las segundas, las entrevistas en profundidad y los grupos de discusión.

Con respecto a la información sociodemográfica, se utilizaron las fuentes estadísticas del Padrón Continuo de Población desde 1998 y Censos de Población y Viviendas de 2011 (INE) (edad, sexo, origen, año de llegada a la vivienda, nacionalidad, nivel de estudios, estructura del hogar, etc.). Desde una perspectiva urbanística, para la caracterización del espacio habitado de los ámbitos seleccionados, además del Censo de Viviendas (instalaciones de la vivienda, número de habitaciones, régimen de tenencia, etc.) se utilizaron los datos de la de la Dirección General del Catastro. La explotación se realizó a partir de la consulta, descriptiva y gráfica, de la información catastral de cada inmueble (año de construcción, superficie útil de la vivienda, usos principales, etc.) (Tabla 1).

Tras la selección de variables sociodemográficas y urbanas procedentes del Censo, Padrón y Catastro, los datos fueron sometidos a procedimientos de estadística descriptiva, (análisis de frecuencia, normalización estadística a partir de fórmulas de dispersión y de estimación de la población y de los hogares y elaboración de tasas e índices y gráficos).

Desde una perspectiva cartográfica, se trabajó a distintas escalas, aunque poniendo el énfasis en la información de carácter inframunicipal (secciones censales y parcelas), a efectos de delimitar los barrios objeto de estudio a partir de la agregación de la información disponible, si bien la menor representación del Censo de 2011 dificultó el acopio de ciertos datos a nivel microescalar. La información se georreferención mediante el programa QGIS (versión 2.18 Las Palmas de Gran Canaria) amparado bajo el Proyecto GNU de aspiración colaborativa, de software libre La integración de la información demográfica y urbanística en dicho sistema de información geodemográfica facilitó el análisis de resultados.

El estudio se completó con un reconocimiento de campo y un inventario fotográfico para afinar en la caracterización del espacio urbano y valorar la funcionalidad y los usos del mismo, así como con procedimientos de trabajo cualitativo. Se realizaron dos entrevistas en profundidad a técnicos en participación ciudadana, una a una trabajadora social con competencias sociosanitarias y una a una activista social involucrada en la cooperación comunitaria. Además, se crearon dos grupos de discusión, uno por cada barrio, con participación de un promedio de quince asistentes de más de sesenta años, jubilados, y algunos familiares, que reunimos en los locales sociales de los 
TABLA 1

DATOS SOCIODEMOGRÁFICOS DE LOS HOGARES Y VIVIENDAS

\begin{tabular}{|c|c|c|c|}
\hline & Escala & $\begin{array}{l}\text { Procedimientos } \\
\text { estadísticos }\end{array}$ & Fuentes \\
\hline Población por edades & $\begin{array}{l}\text { Municipal Inframunicipal } \\
\text { (secciones censales) }\end{array}$ & $\begin{array}{c}\text { Tasas e índices de } \\
\text { envejecimiento y } \\
\text { sobreenvejecimiento }\end{array}$ & $\begin{array}{l}\text { Padrón Continuo } \\
\quad \text { (INE, 2017) }\end{array}$ \\
\hline Estructura por sexo y edad & $\begin{array}{l}\text { Municipal Inframunicipal } \\
\text { (secciones censales) }\end{array}$ & Pirámides de población & $\begin{array}{l}\text { Padrón Continuo } \\
\quad \text { (INE, 2017) }\end{array}$ \\
\hline Nivel de estudios & $\begin{array}{l}\text { Municipal Inframunicipal } \\
\text { (secciones censales) }\end{array}$ & $\begin{array}{l}\text { Proporción de población } \\
\text { según nivel de estudios }\end{array}$ & $\begin{array}{l}\text { Censo de Población } \\
\text { de } 2011 \text { (INE) }\end{array}$ \\
\hline $\begin{array}{l}\text { Año de llegada a } \\
\text { la vivienda }\end{array}$ & $\begin{array}{l}\text { Municipal Inframunicipal } \\
\text { (secciones censales) }\end{array}$ & $\begin{array}{l}\text { Nivel de arraigo de la } \\
\text { población }\end{array}$ & $\begin{array}{l}\text { Censo de Población } \\
\text { de } 2011 \text { (INE) }\end{array}$ \\
\hline Tamaño del hogar & $\begin{array}{l}\text { Municipal Inframunicipal } \\
\text { (secciones censales) }\end{array}$ & $\begin{array}{l}\text { Número medio de } \\
\text { miembros por hogar }\end{array}$ & $\begin{array}{l}\text { Censo de Población } \\
\text { de } 2011 \text { (INE) }\end{array}$ \\
\hline Estructura del hogar & $\begin{array}{l}\text { Municipal Inframunicipal } \\
\text { (secciones censales) }\end{array}$ & $\begin{array}{l}\text { Número medio de } \\
\text { miembros por hogar }\end{array}$ & $\begin{array}{l}\text { Censo de Población } \\
\text { de } 2011 \text { (INE) }\end{array}$ \\
\hline Tamaño de la vivienda & $\begin{array}{l}\text { Municipal Inframunicipal } \\
\text { (secciones censales) }\end{array}$ & \multirow{2}{*}{$\begin{array}{l}\text { Viviendas según intervalos } \\
\text { de superficie del inmueble }\end{array}$} & $\begin{array}{l}\text { Censo de Población } \\
\text { de } 2011 \text { (INE) }\end{array}$ \\
\hline Superficie construida & Parcela catastral & & $\begin{array}{r}\text { Dirección General } \\
\text { del Catastro (2017) }\end{array}$ \\
\hline \multirow{2}{*}{$\begin{array}{l}\text { Año de construcción } \\
\text { del inmueble }\end{array}$} & $\begin{array}{l}\text { Municipal Inframunicipal } \\
\text { (secciones censales) }\end{array}$ & \multirow{2}{*}{$\begin{array}{l}\text { Viviendas según intervalos } \\
\text { de antigüedad del } \\
\text { inmueble }\end{array}$} & $\begin{array}{l}\text { Censo de Población } \\
\text { de } 2011 \text { (INE) }\end{array}$ \\
\hline & Parcela catastral & & $\begin{array}{r}\text { Dirección General } \\
\text { del Catastro (2017) }\end{array}$ \\
\hline \multirow{2}{*}{$\begin{array}{c}\text { Tipología residencial y } \\
\text { otros usos }\end{array}$} & $\begin{array}{l}\text { Municipal Inframunicipal } \\
\quad \text { (secciones censal }\end{array}$ & \multirow{2}{*}{$\begin{array}{l}\text { Número de inmuebles } \\
\text { según intervalos de uso }\end{array}$} & $\begin{array}{l}\text { Censo de Población } \\
\text { de } 2011 \text { (INE) }\end{array}$ \\
\hline & Parcela catastral & & $\begin{array}{r}\text { Dirección General } \\
\text { del Catastro (2017) }\end{array}$ \\
\hline
\end{tabular}

centros de mayores, lo que nos permitió obtener datos sobre sus percepciones, opiniones, actitudes y sentimientos en relación con su barrio. Estos grupos constituyeron una gran oportunidad para poner en común las distintas perspectivas personales sobre cómo se afronta y vive el envejecimiento, pero, sobre todo, para determinar cuál es el grado de identidad y cohesión social de estos barrios en proceso de envejecimiento.

Estudios Geográficos, Vol. LXXIX, 285, pp. 469-500, julio-diciembre 2018

ISSN: 0014-1496, eISSN: 1988-8546, doi: https//doi.org/10.3989/estgeogr.201818 
LOS BARRIOS DE LA PRIMERA INDUSTRIALIZACIÓN Y CONDICIONES HABITACIONALES

\section{Los ciclos de vida de los barrios obreros}

La perspectiva del ciclo de vida tiene una larga tradición en geografía de la población, habiendo fundamentado los estudios generacionales que permiten caracterizar procesos de transición y de cambio a lo largo de los años. Ha sido también un término utilizado en la geografía del turismo, a partir de la definición de las distintas etapas de los destinos turísticos, tal y como fueron concebidas, entre otros, por R. W. Butler (2006). En nuestro caso de estudio, utilizamos este término porque nos permite paralelizar la trayectoria urbana de los barrios objeto de estudio con el ciclo de vida de su vecindario.

Desde esta óptica, las características más significativas de la evolución de San Nicolás y La Isleta en Las Palmas de Gran Canaria, se ajustan a esta secuencia temporal: desarrollo, consolidación y estancamiento, confirmando la premisa defendida por Alguacil, Camacho y Hernández (2014) acerca de que, a lo largo de la historia, las ciudades han desarrollado una reordenación continua de sus espacios a consecuencia de la interceptación del proyecto igualitario de la condición de ciudadanía por el proyecto inmobiliario, que busca el máximo beneficio mediante la segmentación espacial y la reubicación de sus habitantes en función de sus rentas. Así lo han puesto de manifiesto las múltiples investigaciones en el ámbito de la geografía urbana en España, que han interpretado y reinterpretado el crecimiento de las ciudades españolas desde el siglo XIX, ya se trate de las pioneras de Capel (1975), Quirós Linares (1991), Terán (1982), Torres Balbás et al. (1954), Vilá y Capel (1970), etc., como de las más recientes de Hernández Aja et al. (2015), Méndez, Abad y Echaves (2015), Valenzuela (2013), etc.

En las primeras se considera que las transformaciones que origina la revolución industrial en el siglo XIX, pese al limitado y desigual proceso industrializador español, no solo contribuyen a un crecimiento ininterrumpido de la población y del tejido urbanos sino también a un proceso de segregación residencial más intenso, pues más allá del casco antiguo, de los ensanches y de los barrios de ciudad-jardín, la población obrera y los inmigrantes hacen crecer arrabales fuera de ordenación, próximos a la ciudad consolidada. Más adelante en el tiempo, estos espacios se han visto afectados por distinto tipo de procesos que han contribuido a su integración en la trama urbana o a consolidar su posición de marginalidad, en función de que se hayan visto envueltos o no en una nueva centralidad, en acciones especulativas, o a consecuencia de procesos de renovación o sustitución sociodemográficos, así como de las intervenciones en materia de planeamiento, de promoción de viviendas y de acciones de regeneración urbana. 
En cualquier caso, no todos se han visto afectados por la tendencia de fines del siglo XX a acoger a la población que no puede residir en el centro por el alto precio de la vivienda y que necesita de la accesibilidad de los bordes del centro (Calderón, 2001), ya que su evolución ha sido muy desigual y no han sido objeto de una reflexión de conjunto más allá de casos concretos de estudio (Torres y García, 2011).

En Las Palmas de Gran Canaria conviene señalar que, pese a la inexistencia de un proceso industrializador propiamente dicho, el desarrollo de su morfología y estructura urbanas, hasta los años setenta del siglo XX, es muy similar al de la mayor parte de las ciudades españolas. Por ello, pueden definirse como barrios obreros los dos casos de estudio: el primero, el Risco de San Nicolás (Figura 1), un caserío diseminado durante los siglos XVII y XVIII (Quintana Andrés, 2000), que adquirió un notable desarrollo en el siglo XIX, acogiendo a inmigrantes y trabajadores de escaso poder adquisitivo, en una zona de la entonces periferia urbana, separada del centro por huertas de cultivo.

\section{FIGURA 1}

\section{BARRIO DE SAN NICOLÁS}

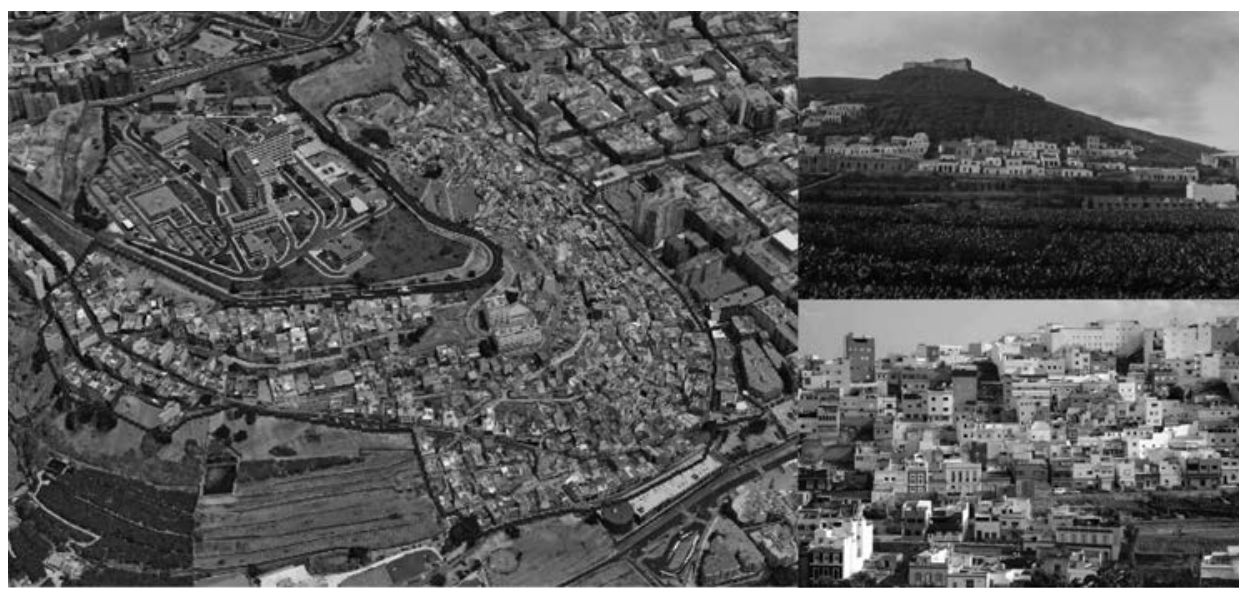

Fuente: Google Earth (2017), FEDAC (1895) y AmiRisco (2017).

Este barrio cumple el patrón de crecimiento insular en ladera: espontáneo, con viviendas de autoconstrucción, mayoritariamente unifamiliares, y que se disponen en una trama irregular, fuertemente determinada por la orografía, con carencia de espacios libres y un sistema viario y de accesos conformado 
por un conjunto de callejones y pasadizos estrechos, escalinatas y calles de gran pendiente (Batista, Hernández e Inglott, 2000). En 1968 ya residían en él 11.102 personas, según el CIES (1970). Sin embargo, es probable que, desde esa fecha, la oferta de vivienda fuera del propio barrio contribuyera a la emigración de sus vecinos hacia otras zonas de la ciudad, iniciándose tempranamente el declive demográfico que confirman las cifras recientes: 4.864 habitantes en 2001 y 3.848 en 2017, y que lo convierten en un barrio que languidece.

El barrio de La Isleta, por su parte, fue un pequeño núcleo de población situado extramuros, en la península del mismo nombre, al abrigo de un complejo montañoso de volcanismo reciente, distante del casco urbano, que contaba con no más de 116 personas en 1874. Sin embargo, la construcción del Puerto de La Luz, a partir de 1883, desencadenó un intenso crecimiento demográfico, propio de una ciudad-hongo. En el padrón municipal de 1910 figuraban ya inscritas 12.117 personas como residentes en La Isleta. Por ello, el Plan de Ensanche, realizado por el arquitecto municipal Laureano Arroyo y Velasco en 1890, que preveía un crecimiento ordenado de este barrio obrero, se vio desbordado por la atracción inmigratoria, con una ocupación libre y laberíntica en chozas, que alojaban a la población que acudía al reclamo de las nuevas actividades portuarias (Domínguez y Gironés, 2001). A medida que avanza el tiempo, las chozas van siendo sustituidas por viviendas de autoconstrucción, viviendas obreras que obedecen a la tipología de casas terreras (Alemán Hernández, 1998) y la estructura urbana ordenada, en cuadrícula, se consolida (Figura 2).

FIGURA 2

\section{BARRIO DE LA ISLETA}

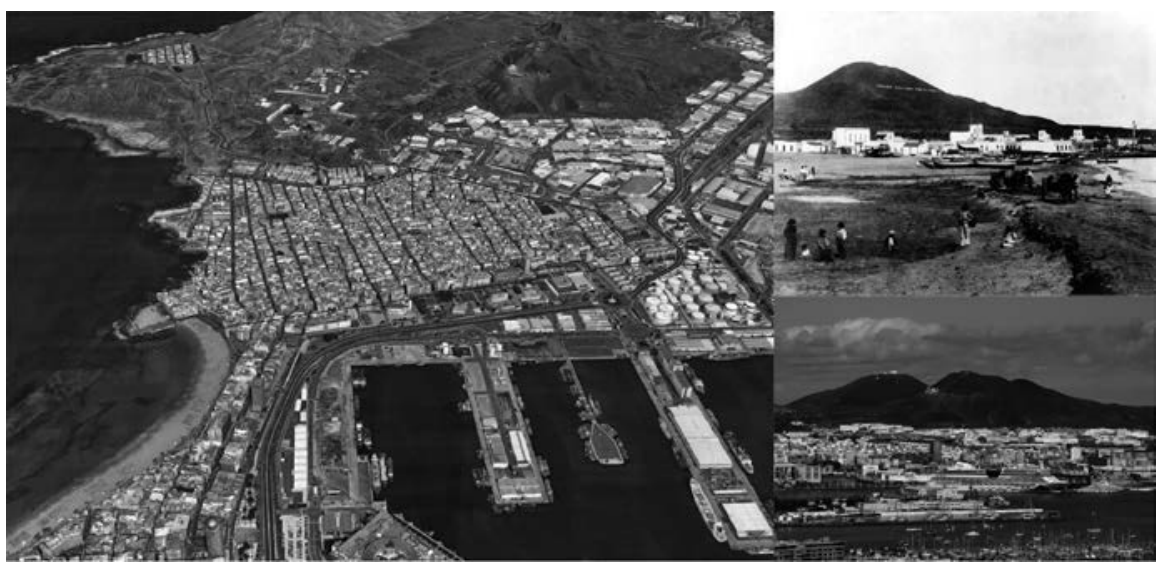

Fuente: Google Earth (2017), Memoria Digital de Canarias, ULPGC (1890) y Antonio Guillén (2010).

Estudios Geográficos, Vol. LXXIX, 285, pp. 469-500, julio-diciembre 2018 ISSN: 0014-1496, eISSN: 1988-8546, doi: https//doi.org/10.3989/estgeogr.201818 
Los años de mayor expansión demográfica de La Isleta se corresponden con los años de postguerra y los primeros del desarrollismo, hasta mediados de los años sesenta del siglo XX. Las promociones de vivienda social afectan a su periferia y a algunos solares del centro del núcleo mientras que el desarrollo turístico, comercial y portuario repercute, fundamentalmente, en la parte baja del barrio, más próxima al recinto portuario y a la playa de Las Canteras. Con posterioridad, desde los años setenta, se registra un cierto declive demográfico, pese a lo cual, desde un punto de vista urbanístico se desarrollan distintas iniciativas públicas y privadas que transforman su fisonomía originaria, al mismo tiempo que las viviendas de autoconstrucción se remozan y muchas aumentan su volumen con nuevas plantas.

Cabe mencionar, como actuaciones públicas de gran trascendencia, en el límite del barrio, en los aledaños del Castillo de La Luz, entre otras: la inauguración de un complejo educativo (IES La Isleta en 1973), sociosanitario (Centro de Salud en 1995), recreativo de carácter específico para mayores (Centro de Mayores en 1999) y general (Castillo de La Luz, reacondicionado como centro de arte en varias etapas de los primeros años del siglo XXI); también conviene mencionar el plan URBAN (1991-1997); la intervención en un sector degradado en el extremo oriental, antigua zona de prostitución (calle Atindana y aledaños), con la construcción y reposición de viviendas a finales de la década de los noventa y la que se realizó a partir de 1998, al oeste, en el borde marítimo de La Puntilla-El Confital, con la construcción un nuevo paseo marítimo y de inmuebles de promoción privada que han favorecido la gentrificación de ese sector urbano (Figura 2).

Desde la perspectiva del ciclo de vida de dichos barrios, en ambos casos se reconoce un desarrollo temprano, espontáneo desde un punto de vista urbanístico, ligado a una intensa inmigración de trabajadores, en el tránsito de los siglos XIX y XX. En décadas posteriores, mejora la urbanización, que se sujeta a ciertas normas, se incrementa la edificación y se consolida el vecindario. Las altas tasas de natalidad de la población y el que sigan constituyendo lugares de atracción inmigratoria garantizan el crecimiento demográfico y urbano de estos barrios en la postguerra.

En los años del desarrollismo español, se aprecia la competencia que representa el crecimiento de nuevas áreas periféricas, con viviendas sociales o de renta libre que se acogen a programas de protección social, lo que va a originar su incipiente decadencia. Comienza a disminuir su población, aunque ciertas iniciativas urbanísticas en sus límites urbanos (las viviendas de San Francisco en San Nicolás en 1962 y de Nueva Isleta en La Isleta en 1955-1958) favorecen la emigración de la población desde el corazón de dichos barrios 
a sus periferias. En cualquier caso, empieza el paulatino proceso de letargo urbanístico y demográfico, con la excepción que supone la inversión privada en la reedificación de ciertos inmuebles y una cierta atracción inmigratoria, mucho más notorios ambos procesos en La Isleta que en San Nicolás.

En una etapa postfordista, la atonía urbana y demográfica caracteriza al barrio de San Nicolás. La mayor parte de los vecinos que compraron solares, construyeron sus casas o se trasladaron desde otros lugares a las ya edificadas, en los años cuarenta y cincuenta, constituyen el grueso de la población envejecida del barrio. Muchos de sus descendientes emigraron en la década de los años sesenta y posteriores, lo que ha contribuido al aumento de hogares de personas solas, tal y como confirmaron las entrevistas a los ancianos del barrio y los grupos de discusión. Por otra parte, las dificultades topográficas mencionadas, en un contexto de creciente necesidad de desplazamiento rodado, han impedido la revalorización del suelo urbano. Además, la incapacidad de las sucesivas administraciones para intervenir de forma que se dignifiquen las condiciones residenciales, también ha influido en su pérdida de atractivo, tal y como pone de manifiesto el hecho de que sea muy reducida la proporción de la población extranjera que se ha afincado en el barrio $(4,8 \%)$, hasta el punto de que el mercado de suelo y las transacciones inmobiliarias son muy limitadas. El estigma de barrio marginal, a consecuencia de la etapa en que se construyeron chabolas en sus aledaños (años ochenta y noventa), y se prodigaron las actividades delictivas ha supuesto un lastre añadido para que se activen nuevas dinámicas demográficas y urbanas.

En el caso de La Isleta, desde la década de los años setenta se producen sucesivas operaciones de rehabilitación y regeneración urbanas, tal y como se ha mencionado, lo que demuestra que se trata de un barrio vivo, en el que se reconocen, a microescala, muchas de las intervenciones propias de la ciudad del desarrollismo: la edificación de bloques y torres (calle Juan Rejón, inmuebles de los trabajadores portuarios, etc.) y de la ciudad postfordista: desarrollo de actividades de restauración y hostelería (calles La Naval, Juan Rejón, paseo de La Puntilla), apertura de nuevas áreas recreativas y de dotaciones educativas y sociosanitarias, mejoras en el viario, etc. Estas actuaciones coinciden con nuevas dinámicas demográficas, en un vecindario de 20.642 personas, porque, pese a la contracción del crecimiento natural, el barrio se vuelve atractivo para extranjeros $(7,7 \%$ de residentes, a cierta distancia del $6,4 \%$ de población extranjera en el conjunto del municipio) y no solo para los de menor poder adquisitivo, pues la plurifuncionalidad (comercio, ocio, restauración, turismo, etc.) origina una mayor heterogeneidad social y de orígenes geográficos (conviven en La Isleta ciudadanos llegados desde veintiocho países distintos). 
Por tanto, se aprecia una diferenciada evolución en los últimos años que dota a este espacio de unas mayores perspectivas de futuro.

\section{Las condiciones habitacionales}

La localización de San Nicolás en un cantil costero fosilizado, de pronunciada pendiente, y un origen urbanístico de crecimiento espontáneo, fuera de normativa, han supuesto un desafío para la ocupación residencial y para la edificabilidad, favoreciendo la configuración de un barrio con una trama irregular y abigarrada. Por tanto, los mayores problemas del barrio derivan de la propia orografía, de una edificabilidad agotada, de un limitado sistema de accesos así como de un notable deterioro de los inmuebles. En definitiva, el tejido urbano que lo caracteriza dificulta la capacidad de actuación de los órganos competentes de la Administración en materia de planificación que no han podido idear intervenciones que modifiquen sustancialmente las condiciones residenciales.

Por lo que respecta al deterioro de los inmuebles, algunas situaciones alcanzan niveles extremos, con viviendas habitadas aunque apuntaladas, lo que informa de una realidad aún más preocupante pues, si a la vulnerabilidad que representa el que muchas personas mayores vivan solas, sumamos la inhabitabilidad de los edificios, el panorama es de auténtica emergencia social. Por otro lado, la densificación de viviendas en San Nicolás, con un escaso porcentaje de suelo libre, más la ya mencionada dificultosa orografía, impiden una correcta distribución de equipamientos municipales y de servicios. La ausencia de espacio público y la difícil comunicación inciden de manera negativa en los ancianos, usuarios preferentes de dicho espacio y que necesitan tener facilidades para desplazarse. Ante el problema de las calles de elevada pendiente, la respuesta de la Administración debiera ser la de ofrecer áreas de descanso, que les facilitaran a los vecinos el trayecto de subida hacia las partes más altas del Risco, así como más espacio para zonas de esparcimiento. Entre otras, son reivindicaciones frecuentes las de que se dé solución a los problemas de movilidad. «San Juan cuenta con una guagua pequeña que recorre el barrio, ¿nosotros por qué no?» [Anónimo, 1 de junio de 2017].

Por su parte, muchas son las iniciativas que han acometido los propios vecinos por mejorar su entorno. Algunas calles muestran labores de embellecimiento, pues han sido engalanadas por ellos con elementos reciclados, macetas, pinturas y otro tipo de adornos, mientras que la instalación de escaleras mecánicas por parte de la Administración, para facilitar el acceso a ciertos sectores urbanos, 
se ha revelado insuficiente e ineficaz (se han deteriorado rápidamente, están fuera de funcionamiento durante varios días, etc.)

Adoptando la perspectiva de microescala, en la ya mencionada sección censal más envejecida, situada en la parte alta del Risco, el 84,2\% de las viviendas corresponde a casas terreras entre medianeras; inmuebles antiguos (el 45\% fueron construidos con anterioridad a 1950) deficientemente conservados (Figura 3). En cuanto a su tipología, se trata de viviendas unifamiliares de 1 o 2 plantas, si bien es cierto que algunas han ido ganando altura, como casas crecederas, reconvirtiéndose en inmuebles de 2 a 4 viviendas. Junto a ellas, se halla la única actuación de viviendas de renta baja del barrio, llevada a cabo por el Patronato Benéfico de Construcción Francisco Franco en 1965: bloques de 5 plantas, con un total de 60 viviendas de superficie útil inferior a $50 \mathrm{~m}^{2}$ y con un sistema de acceso infradotado (sin ascensores, con escalinatas desde la calle) y deficiente estado de conservación (Figura 4).

\section{FIGURA 3}

ANTIGÜEDAD MEDIA DEL INMUEBLE EN LA MANZANA (SAN NICOLÁS)

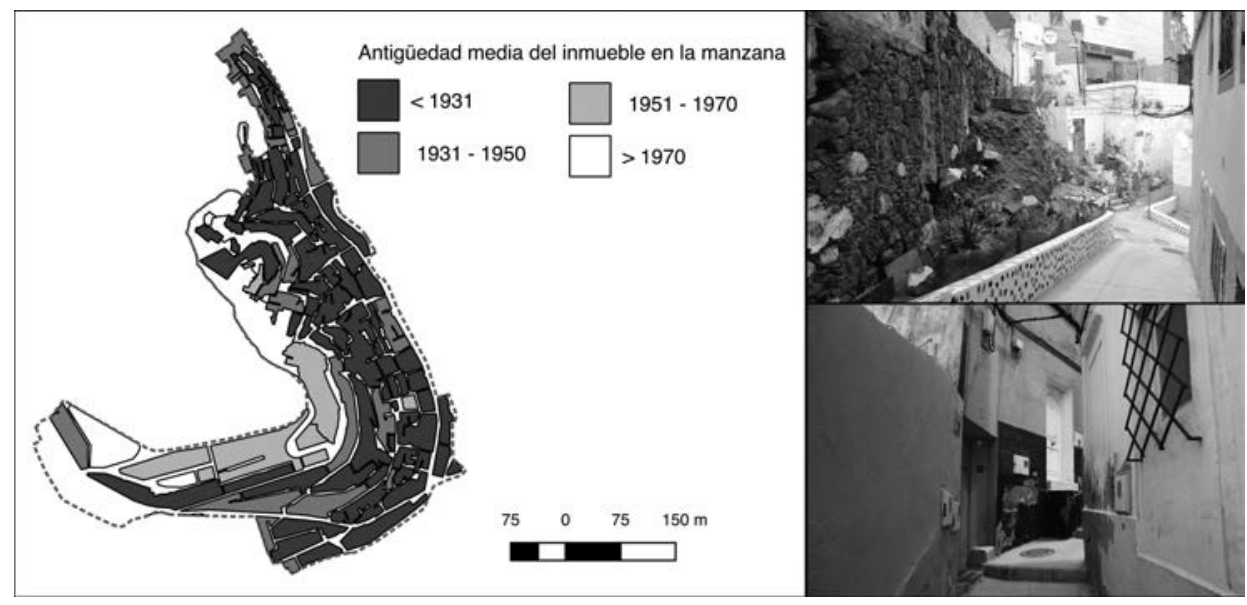

Fuente: Dirección General del Catastro (2017). Elaboración propia. Fotos: autores.

De la dificultad que representan estas condiciones habitacionales se hacen eco los vecinos entrevistados. "Vivo en un quinto piso sin ascensor y me supone mucho esfuerzo subir las escaleras. Estoy buscando casa en un bajo y no descarto la idea de irme fuera del barrio» [Anónimo, 15 de junio de 2017]. «La accesibilidad ha mejorado ligeramente, pero las pendientes siguen suponiendo un peligro» [Anónimo, 15 de junio de 2017]. 
FIGURA 4

PROMEDIO DE VIVIENDAS POR INMUEBLE EN LA MANZANA (SAN NICOLÁS)

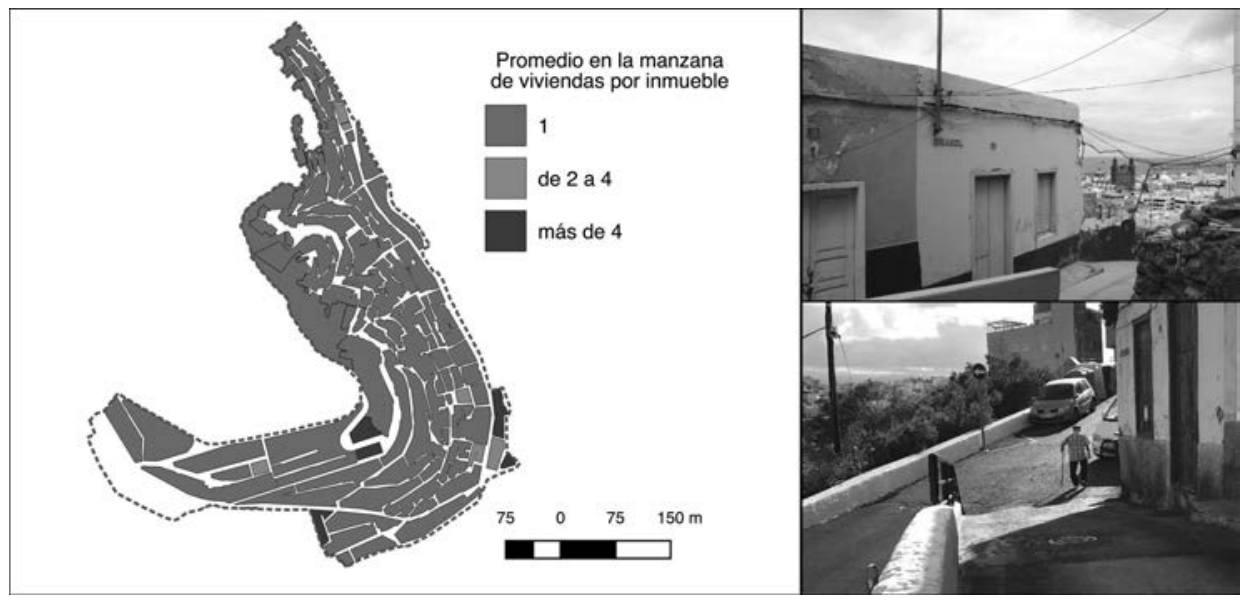

Fuente: Dirección General del Catastro (2017) Elaboración propia. Fotos: autores.

En cuanto al barrio de La Isleta, desde el punto de vista de su fisonomía, su trama es mayoritariamente ortogonal y su tejido urbano es más híbrido. Cuenta con viviendas unifamiliares de autoconstrucción, muchas de las cuales han ganado altura; con otros edificios colectivos, de nueva planta; y con un mayor número de inmuebles procedentes de actuaciones de vivienda barata de distintas etapas. Todo ello demuestra una mayor vitalidad urbana: una mayor preocupación por parte de las instituciones para dar respuesta a la demanda de vivienda social en un barrio de trabajadores portuarios, un poder adquisitivo de sus vecinos relativamente mayor y una transferencia de la actividad económica comercial y turística que ha afectado a sus límites occidental y meridional, originando una morfología urbana más heterogénea y un vecindario más cosmopolita.

No obstante, los niveles de densidad de la trama urbana de La Isleta son elevados y el deterioro de los inmuebles se reconoce en ciertos sectores. El sistema de movilidad peatonal está mal resuelto, con aceras estrechas, inadecuada distribución de los pasos peatonales, e invasión del espacio público por los vehículos rodados. Esto último, entorpece el tránsito peatonal de algunas calles, a la vez que sitúa a la persona mayor en una situación de vulnerabilidad y riesgo, al obligarla a continuar su trayecto por el asfalto. La pendiente también supone un esfuerzo para el peatón que debe acceder a las partes más altas del barrio, pero, en ningún caso, presenta las dificultades que 
se observan en el Risco de San Nicolás. Además, las menores pendientes y la trama ortogonal hacen que se haya podido resolver mejor la movilidad, por lo que ha contado, desde los años sesenta, con un servicio de transporte público que conecta el barrio con el resto de la ciudad.

Por otra parte, La Isleta carece de espacios libres en su interior, que supongan una alternativa al tupido conjunto edificatorio, y que ofrezcan opciones de ocio y esparcimiento, dada la escasez de zonas verdes, de ámbitos abiertos y de ornato urbano, aunque también es cierto que se han desarrollado algunas pequeñas intervenciones en huecos vacíos de la trama urbana y, lo que es más importante, que la cercanía a la playa de Las Canteras, La Puntilla y El Confital, a la zona abierta del Castillo de La Luz, limítrofe con el recinto portuario, además del Paisaje Protegido de La Isleta, sean escenarios que han contribuido a esponjar los límites del barrio y que constituyen un auténtico privilegio para su población.

\section{FIGURA 5}

ANTIGÜEDAD MEDIA DEL INMUEBLE EN LA MANZANA (LA ISLETA)

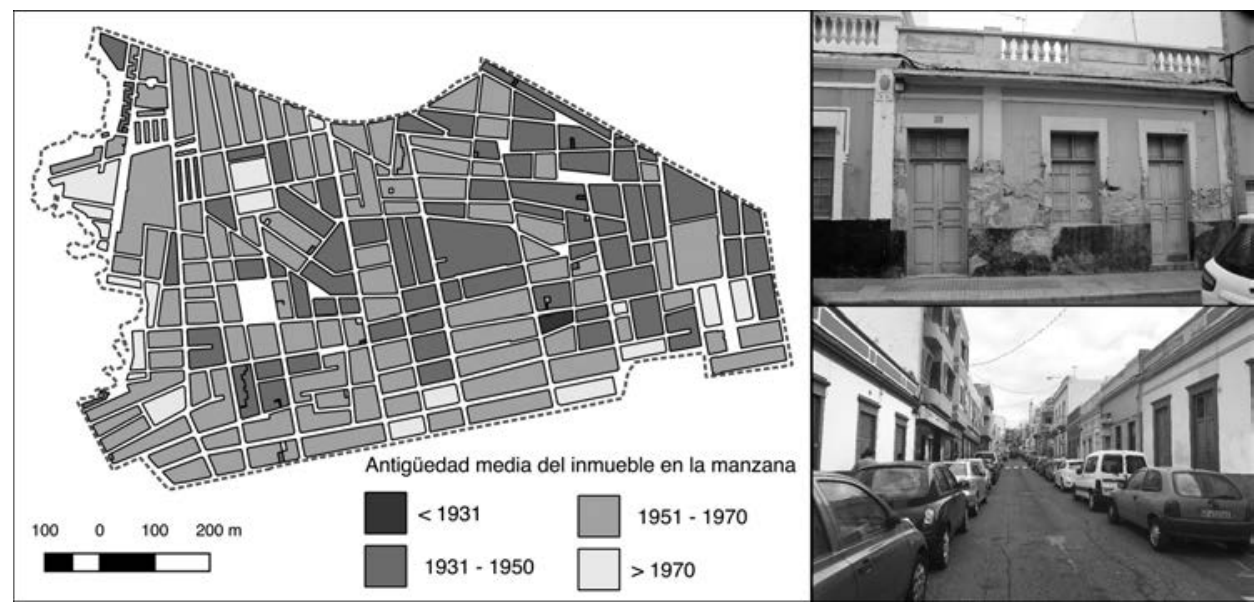

Fuente: Dirección General del Catastro (2017). Elaboración propia. Fotos: autores.

Este sector de la ciudad reúne numerosos inmuebles de tipología tradicional que le confieren valor patrimonial, pero que presentan un defectuoso estado de conservación, en ciertos ámbitos. Según datos catastrales, La Isleta se configura como un espacio de cierta hibridez tipológica, en el que el 55\% de los inmuebles tiene menos de dos plantas. En él hay viviendas unifamiliares 
de autoconstrucción y dos promociones de vivienda pública: el grupo de casas baratas Capitán García López, proyectado en 1937 por la extinta sociedad municipal Junta General del Paro, y que corresponde a veinte viviendas unifamiliares adosadas (Martínez Zimmermann, 2011); y el bloque de viviendas en manzana abierta de Fermín Sanz Orrio, que data de 1954, y cuyo promotor fue la Obra Sindical del Hogar. Un 64\% de los inmuebles son unifamiliares, el $15 \%$ son de dos viviendas, y el 22\% restante, viviendas colectivas. En cuanto a la superficie útil, un 33\% de las viviendas no supera los $60 \mathrm{~m}^{2}$ (Figuras 5 y 6).

FIGURA 6

PROMEDIO DE VIVIENDAS POR INMUEBLE EN LA MANZANA (LA ISLETA)

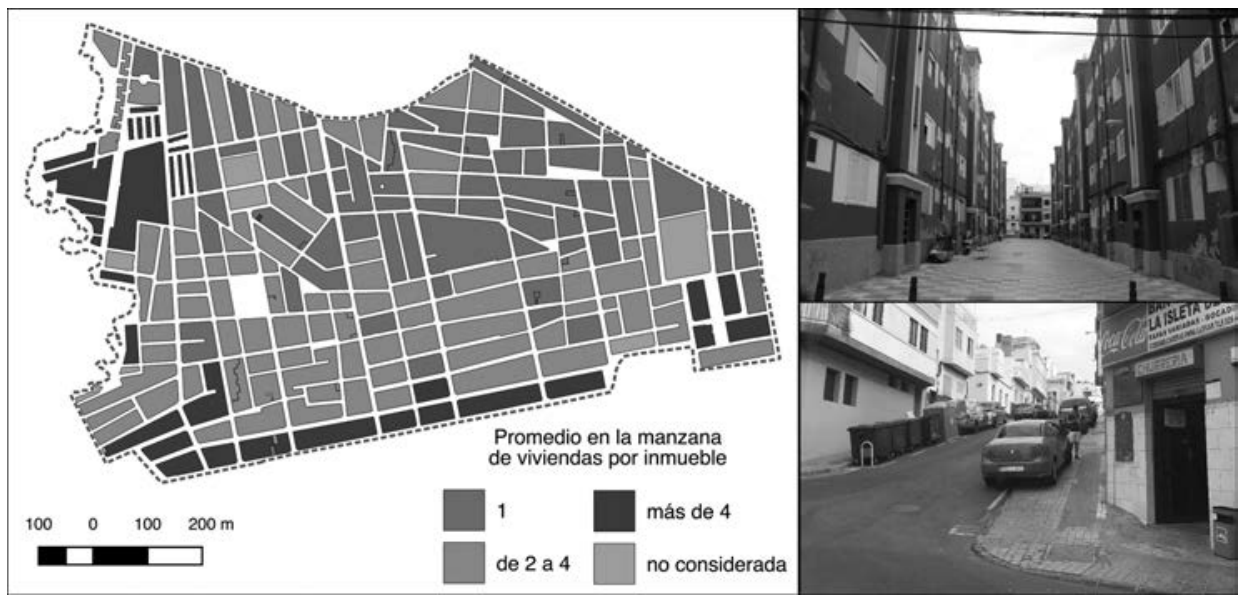

Fuente: Dirección General del Catastro (2017). Elaboración propia. Fotos: autores.

ENVEJECIMIENTO DEMOGRÁFICO Y CARACTERÍSTICAS SOCIODEMOGRÁFICAS DE LA POBLACIÓN ENVEJECIDA

\section{El envejecimiento demográfico}

Las tasas de envejecimiento y sobreenvejecimiento de los barrios analizados están ligeramente por encima de las del conjunto municipal, al mismo tiempo que los índices de envejecimiento y sobreenvejecimiento revelan una tendencia más acentuada de estos procesos (Tabla 2). También lo corroboran las pirámides de población (Figuras 7 y 8), que nos hacen anticipar la próxima consolidación del proceso de envejecimiento demográfico. 
TABLA 2

INDICADORES DE ENVEJECIMIENTO Y SOBREEVEJECIMIENTO (2017)

\begin{tabular}{lccc}
\hline & San Nicolás & La Isleta & \multicolumn{2}{c}{$\begin{array}{c}\text { Las Palmas de } \\
\text { Gran Canarias }\end{array}$} \\
\hline Población de 65 años y más (\%) & 17,67 & 21,57 & 17,53 \\
\hline Población de 75 años y más (\%) & 9,56 & 10,42 & 7,98 \\
\hline Población de 85 años y más (\%) & 2,55 & 2,97 & 2,19 \\
\hline Población de 95 años y más (\%) & 0,23 & 0,20 & 0,18 \\
\hline Índice de envejecimiento (\%) & 144,37 & 203,10 & 138,23 \\
\hline Índice de sobreenvejecimiento (\%) & 54,12 & 48,32 & 45,54 \\
\hline İndice de dependencia de los viejos (\%) & 25,21 & 31,80 & 25,12 \\
\hline
\end{tabular}

FIGURA 7

\section{PIRÁMIDE DE POBLACIÓN DE SAN NICOLÁS}

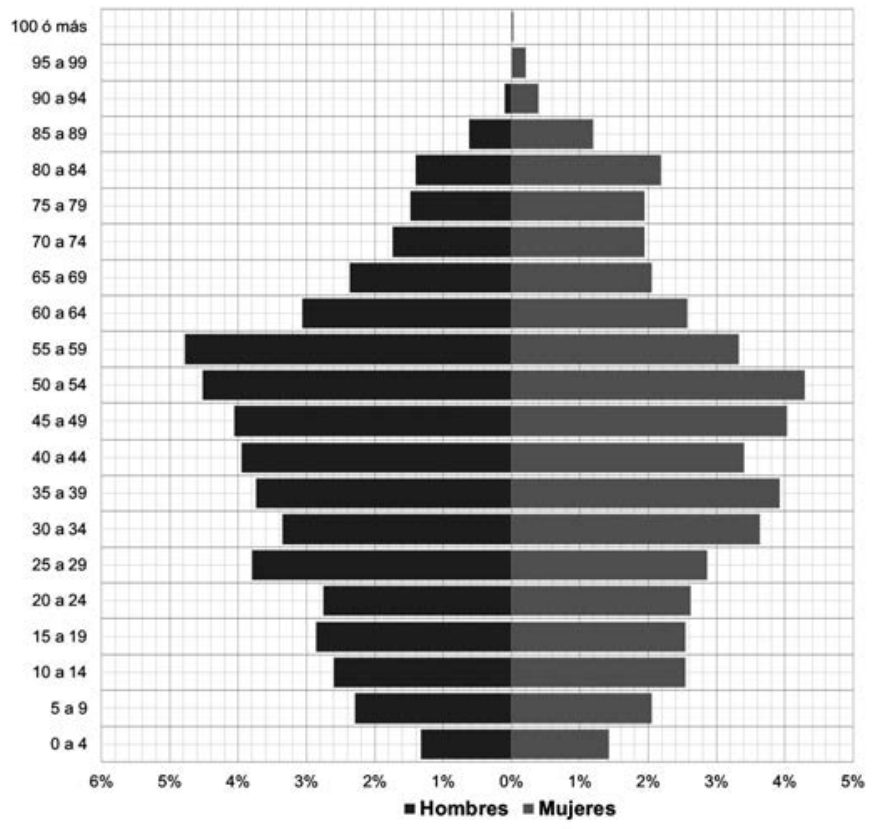

Fuente: INE. Padrón Continuo (2017). Elaboración propia.

Estudios Geográficos, Vol. LXXIX, 285, pp. 469-500, julio-diciembre 2018 ISSN: 0014-1496, eISSN: 1988-8546, doi: https//doi.org/10.3989/estgeogr.201818 
Como puede apreciarse en ellas, tanto en San Nicolás como en La Isleta, la cohorte más numerosa es la de 50 a 54 años, advirtiéndose una contracción paulatina de las generaciones posteriores, con un mínimo en el grupo de 0 a 5 años. Llama la atención esa marcada tendencia a la reducción de la población adulta y joven, que ha de interpretarse no solo como consecuencia de la disminución de las tasas de fecundidad y natalidad (que afectaría a cohortes más jóvenes, pues se produce desde mediados de los setenta y ochenta del siglo XX) sino por el menor balance migratorio. Por su parte, con respecto a la población de más de 65 años, se puede apreciar que, pese a las irregularidades propias de una estructura demográfica con un pequeño número de efectivos, los residentes más longevos están bien representados hasta los 84 años, sobre todo en el caso de La Isleta.

FIGURA 8

\section{PIRÁMIDE DE POBLACIÓN DE LA ISLETA}

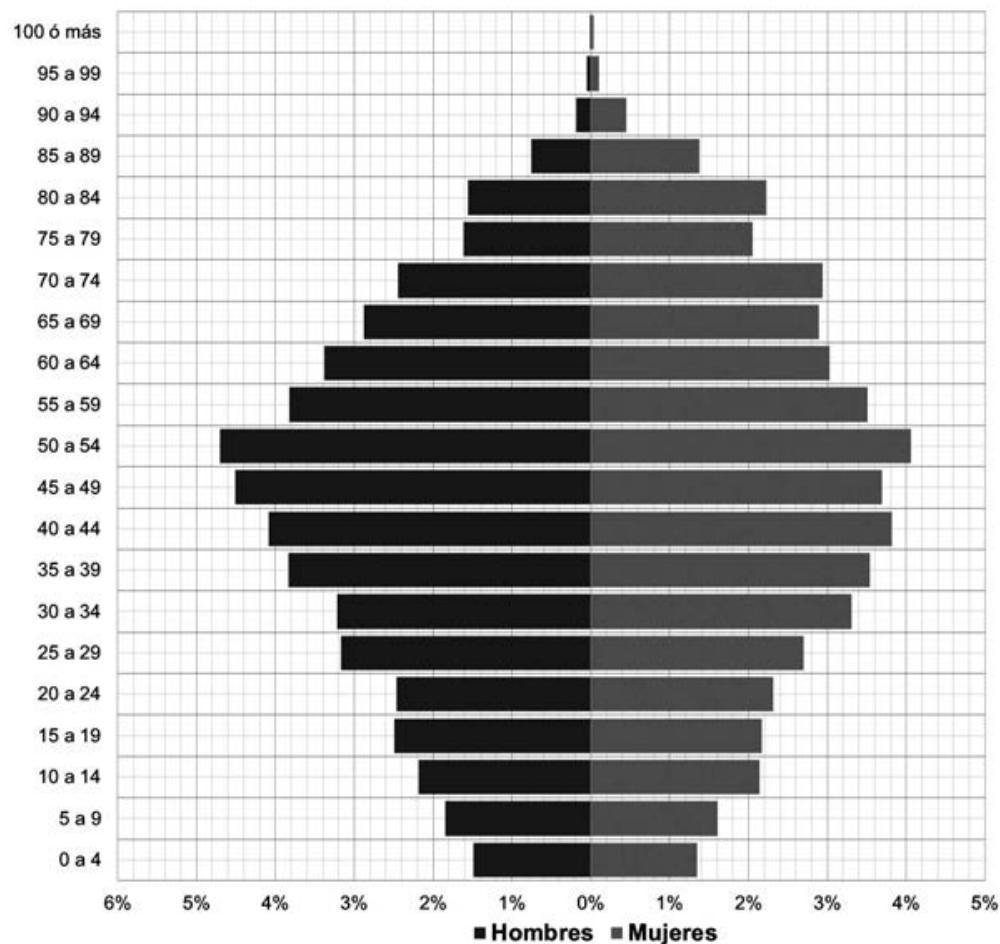

Fuente: INE. Padrón Continuo (2017). Elaboración propia.

Estudios Geográficos, Vol. LXXIX, 285, pp. 469-500, julio-diciembre 2018

ISSN: 0014-1496, eISSN: 1988-8546, doi: https//doi.org/10.3989/estgeogr.201818 
Desde una perspectiva de conjunto, las generaciones más numerosas corresponden a las de los años de expansión demográfica y urbanística de los barrios analizados, los de postguerra y primer desarrollismo. De ahí su huella en las cohortes mencionadas (los descendientes de los que allí se trasladaron en esa etapa).

Desde una perspectiva de detalle, los mayores índices de envejecimiento y sobreenvejecimiento en San Nicolás se registran en la sección censal que se sitúa en la margen izquierda de la calle homónima, próxima al Hospital Militar. Por su parte, La Isleta concentra una tendencia mayor hacia el envejecimiento en su litoral, en la zona de La Puntilla, y al sur de la urbanización de Nueva Isleta, mientras que las zonas menos sobreenvejecidas corresponden al conjunto de las secciones meridionales, con una mayor proporción de población extranjera.

\section{Características sociodemográficas de la población envejecida ${ }^{4}$}

Hemos seleccionado tan solo algunos de los datos censales de carácter sociodemográfico de la población envejecida que nos han parecido más interesantes: su nivel de estudios (como indicador de estatus socioeconómico), la estructura del hogar (formas de convivencia) y el año de llegada al municipio y a la vivienda (por su repercusión en el sentimiento de identidad).

Con respecto al primero, la población anciana que no ha superado estudios de primer grado equivale a un 69\% en el caso de San Nicolás y a un $68 \%$ en el de La Isleta, por tanto, se trata de dos grupos prácticamente equivalentes, sin embargo, desde el punto de vista de su composición interna, en el primero, los analfabetos alcanzan una cifra superior (11\% frente a $8 \%$ ) y también aquéllos sin estudios (37\% frente a 28\%), mientras que en La Isleta los que cursaron estudios de primer grado representan un 32\% frente a tan solo el $21 \%$ de San Nicolás. El paralelismo entre los niveles de formación de la población y el nivel socioeconómico de los barrios (que revelan indicadores como el de la riqueza catastral) valida la mayor situación de marginalidad socioeconómica de San Nicolás, especialmente notable en el caso de la población envejecida, circunstancia que ha de valorarse también a efectos de la menor capacidad de las personas menos formadas para acceder a los servicios.

4 Los datos de estructura por sexo y edad, origen geográfico y nacionalidad proceden del Padrón, 2017. Sin embargo, las demás variables sociodemográficas se tomaron del Censo de 2011. Por tanto, corresponden a una población que era anciana hace más de siete años. 
En relación con las estructuras de convivencia de los ancianos, predomina el hogar formado por una pareja sin hijos, tanto en uno como en otro barrio, aunque en el segundo alcanza una cifra más alta (34\% frente a 19\%), otro signo de la mayor vulnerabilidad que refleja la información sociodemográfica de San Nicolás. En ambos barrios tienen también un peso destacado los hogares de una persona sola, especialmente los hogares de una mujer sola. La soledad, o la vejez en compañía de otro anciano, son datos añadidos que deben considerarse en la planificación de servicios.

Finalmente, por lo que respecta a si se trata de una población que ha podido desarrollar sentimientos de arraigo, los indicadores censales parecen confirmarlo, pues una cifra próxima a un $90 \%$ de los ancianos de cada uno de estos barrios vive en el municipio desde antes de 1971 (el dato más antiguo que proporciona el censo) y un $50 \%$ de ellos reside en la misma vivienda desde esos cuarenta años atrás. No cabe duda, por tanto, del vínculo que han podido establecer con el barrio y con su vivienda a la largo de una gran parte de su existencia.

\section{DOTACIONES SOCIO-SANITARIAS Y SERVICIOS COMPLEMENTARIOS}

\section{La estructura socio-sanitaria}

En Las Palmas de Gran Canaria, los mecanismos político-sociales que con más éxito tratan de paliar los efectos del envejecimiento corresponden a las prestaciones que ofrecen la Ley de Dependencia y el Servicio de Ayuda a Domicilio y de ellos se vale un buen número de los ancianos de dichos barrios, aunque el mencionado Servicio de Ayuda a Domicilio se redujo en los años de la crisis (2011-2013), advirtiéndose una cierta mejora a partir de 2014.

Estos servicios sociales responden a un sistema cerrado, con protocolos de actuación e intervención estructurados, en los que influye más el trámite que la mediación y cuyos procedimientos de intervención están debidamente estipulados y regulados por ordenanzas municipales, de forma que el protocolo prevalece sobre la emergencia social. Las consecuencias directas de la gran demanda de estos servicios y de las largas esperas que supone la concesión del grado de dependencia o de la adjudicación del Servicio de Ayuda a Domicilio, repercuten en una sobrecarga en el sistema de salud que, prolongando la permanencia de algunos ancianos en hospitales, tratan de evitar situaciones de desamparo y generan la frustración de las familias y el enfado con el sistema. «Lamentablemente, los trámites llevan su tiempo, y mientras tanto, se intentan buscar vías alternativas» [Trabajadora social, 27 de junio de 2017]. 
Estas circunstancias se han convertido en un reto para el sector de la salud y de la esfera socio-asistencial, en los que descansa la garantía de bienestar de las personas mayores.

\section{Las dificultades de acceso a los servicios y las vías de apoyo informal}

Por otra parte, en los casos estudiados, la red de apoyo familiar supone un complemento fundamental para la atención a los mayores, aunque con diferencias en la intensidad y ocurrencia del funcionamiento de dicha red, pues la fortaleza de la estructura generacional es mayor en La Isleta (con un mayor porcentaje de hogares en los que vivían 3 o más generaciones de una misma familia en 2011), por lo que la ayuda que presta la familia a sus abuelos dependientes es también mayor, aunque no se pueden olvidar ciertas situaciones de extrema vulnerabilidad que, según los técnicos con competencias sociosanitarias en el barrio, se dan en aquellos hogares donde el anciano vive en estado de confinamiento y en aquellos otros casos en los que el cuidador o cuidadores son ancianos.

Por oposición, en San Nicolás, a la menor representación de hogares con varias generaciones, se suma un deterioro más acentuado del tejido residencial y medioambiente urbano, así como una orografía que dificulta la movilidad, todo lo cual ha hecho que muchas personas mayores hayan optado por abandonar el barrio. Los que se han quedado en él se hallan en una situación de desamparo familiar, que intentan atenuar los servicios sociales e, incluso, la propia comunidad. En consecuencia, se observan actitudes solidarias para con ellos de sus vecinos, para facilitarles el aprovisionamiento de alimentos y medicamentos, para prepararles la comida, para trasladarles la basura a los respectivos contenedores y también labores de acompañamiento, al mismo tiempo que el voluntariado, a través de distintas organizaciones sin ánimo de lucro, conforma una red de apoyo complementario fundamental (Cáritas y la Fundación Farrah, entre otras).

LOS SENTIMIENTOS DE IDENTIDAD DE LA POBLACIÓN ANCIANA Y EL PAPEL DE LA COMUNIDAD

\section{La pertenencia e identidad ambiental}

Los factores que inciden en el sentimiento de pertenencia a un lugar, y que dotan de una identidad propia a un barrio, son muchos. De manera general, 
radican en razones históricas que, por circunstancias específicas del transcurso del tiempo, han ido configurando un rasgo sociocultural que descansa en lazos y pautas de comportamiento propias de grupos sociales cohesionados. Asimismo, cuestiones como el aislamiento y los sentimientos de extrañeza con otros núcleos de población, la marginalidad, o los valores socio-culturales y/o naturales endógenos, crean necesidades comunes de las que surgen la solidaridad y la defensa de lo propio.

Los dos ámbitos de estudio guardan un sentimiento de pertenencia de casuística similar, pero con cierto grado de diferencia entre ellos. La Isleta se caracteriza por ser uno de los barrios con más sentido del arraigo de la ciudad, mientras que San Nicolás sufre un notable deterioro social que merma su identidad, por la mengua de las condiciones de vida y la pauperización extrema. Pese a ello, muchos de los entrevistados definen a los «risqueros» como una gran familia, aunque también lamentan la falta de unión que llevan experimentando desde hace unos años, así como las connotaciones peyorativas que ha representado ser del barrio para los jóvenes, pues la situación de segregación residencial que supuso el chabolismo y la ocupación por grupos marginales de algunos inmuebles ha derivado en sentimientos endofóbicos. A este respecto, una exalcaldesa de la ciudad, evitaba mencionar el nombre de este, su barrio de nacimiento, refiriéndose a él como «Triana Alta».

La naturaleza solidaria de este Risco tiene sus raíces a principios de siglo $\mathrm{XX}$, con los primeros movimientos obreros y sindicales de Las Palmas de Gran Canaria. Las dificultades y necesidades estructurales del barrio fueron conformando un clima de malestar social que desembocó en la fundación de la Sociedad de los Veinte, un movimiento vecinal de clase obrera y de carácter republicano. Posteriormente, en los años de la posguerra nació la Sociedad Polonia, cuyo papel en la comunidad mantuvo vivo el espíritu de los «risqueros», organizando actividades culturales, entre las que destacaban las clandestinas de los bailes de carnaval (Batista, Hernández e Inglott, 2000). Hoy, son varios los colectivos que funcionan en el Risco, y también variadas las formas y finalidades de sus asociaciones (festivas, culturales, deportivas, vecinales, asistenciales, etc.) Por ello se puede afirmar que San Nicolás conserva un tejido social de cierta entidad, gracias a las labores que llevan a cabo las agrupaciones organizadoras de eventos como RisqueAndo, también con motivo de las fiestas patronales del barrio, o con las oportunidades de relación social del Centro de Mayores Párroco Manuel Romero.

La identidad de barrio de La Isleta radica en circunstancias similares, «nace con su propio origen humilde y obrero» y las necesidades de su población se plasmaron, tempranamente, en numerosas reivindicaciones que demandaban 
una mejora en las condiciones de vida del barrio. Además, el contacto con el puerto ha definido, trascendentalmente, al «isletero», pues el trasiego portuario de antaño, también venía acompañado de aires frescos desde otras latitudes.

Por tanto, el sentimiento de pertenencia y el espíritu reivindicativo que exhibe el vecindario debe ser considerado un gran valor, un mecanismo de defensa que se mantiene de manera latente y abanderan desde los más jóvenes hasta los más viejos. Las declaraciones del conocido humorista Manolo Vieira, recordando con orgullo sus orígenes isleteros, ilustran este sentimiento. Numerosos son los colectivos, asociaciones y agrupaciones socio-culturales que otorgan al barrio una identidad propia y bastante conocida por el resto de los ciudadanos. Además, las iniciativas colaborativas, tal y como afirman los técnicos de participación ciudadana del Distrito Puerto-Canteras, suelen contar con un porcentaje elevado de apoyo (Figuras 9 y 10).

FIgURA 9

JORNADAS RISQUEANDO EN SAN NICOLÁS

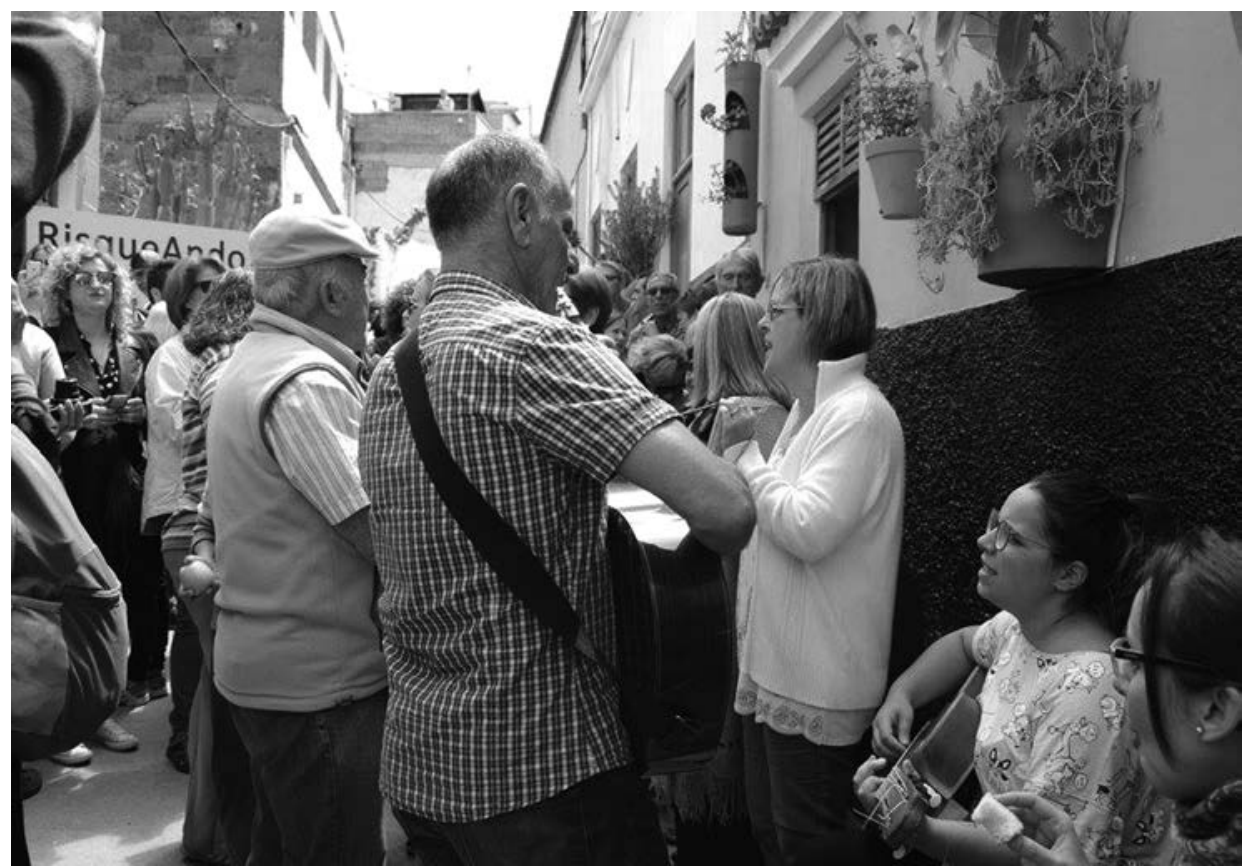

Fuente: AmiRisco (2017).

Estudios Geográficos, Vol. LXXIX, 285, pp. 469-500, julio-diciembre 2018 ISSN: 0014-1496, eISSN: 1988-8546, doi: https//doi.org/10.3989/estgeogr.201818 
FIGURA 10

FIESTAS DEL CARMEN EN LA ISLETA

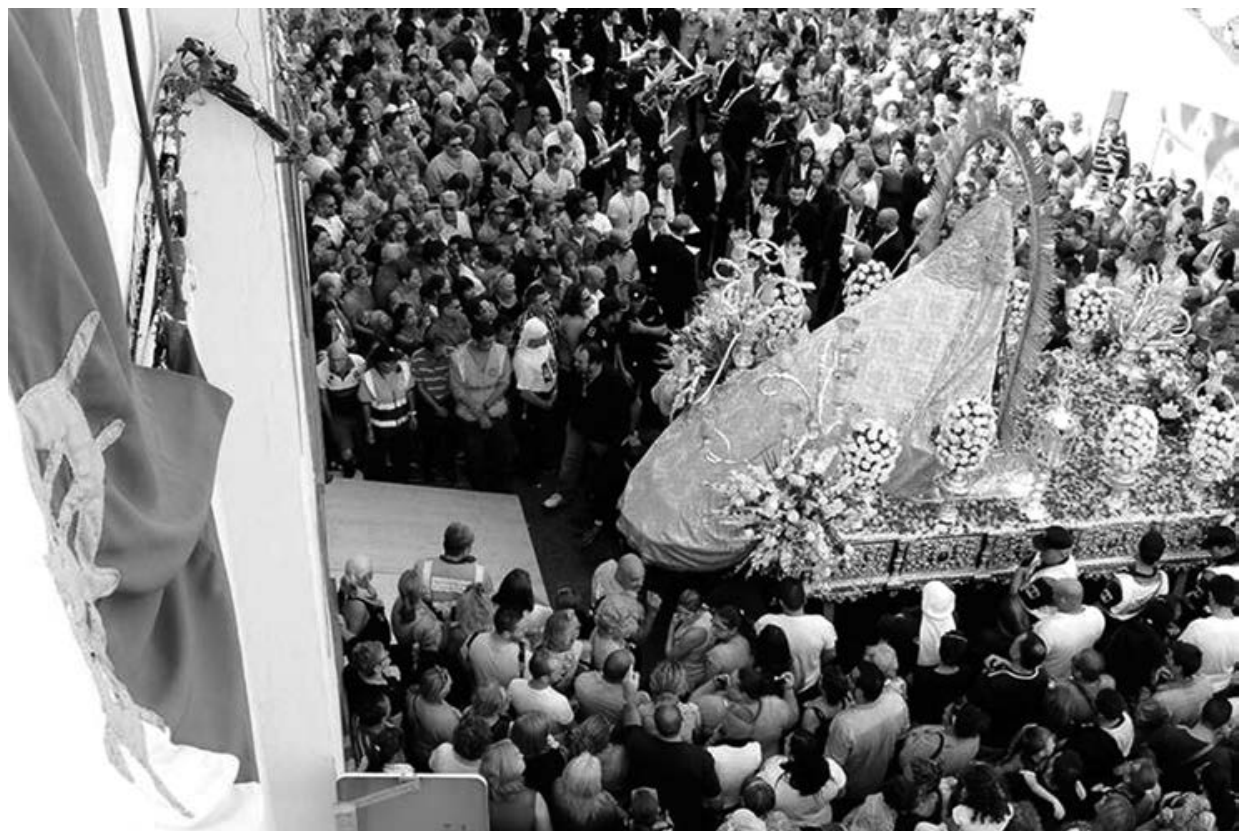

Fuente: Conoce La Isleta (2014).

\section{El compromiso comunitario frente al envejecimiento}

Superar la barrera de los 60 años inquieta a los que comienzan su andadura en la tercera edad o están a las puertas de su jubilación. Por un lado, les preocupa que su salud pueda verse drásticamente comprometida y les impida seguir realizando una vida con normalidad y, por otra parte, se niegan a adoptar hábitos sedentarios cuya única rutina resida en contemplar el paso del tiempo. En las entrevistas y los grupos de discusión, las personas en edades comprendidas entre los $60^{5}$ y 75 años observan con cierta compasión a los más longevos, y se lamentan por la situación de desgana que dicen reconocer en estos últimos. De hecho, es necesario distinguir ambos grupos

5 Aunque en España se establece que la población envejecida es aquella comprendida entre 65 y más años, nos pareció conveniente rebajar el umbral a los jubilados de más de 60 años, para los grupos de discusión.

Estudios Geográficos, Vol. LXXIX, 285, pp. 469-500, julio-diciembre 2018

ISSN: 0014-1496, eISSN: 1988-8546, doi: https//doi.org/10.3989/estgeogr.201818 
etarios, dadas las diferencias de sus demandas. Los primeros, nacidos a fines de los cuarenta o en los años cincuenta del siglo XX, tienen un perfil socioformativo más cualificado y tuvieron, en general, una juventud menos dura que los del segundo grupo. Rehúsan hablar del fin de una etapa, ni siquiera quieren definirlo como un nuevo ciclo en sus vidas, sino de una continuación de lo que vienen haciendo hasta ahora, con la salvedad de disponer de más tiempo libre. Por su parte, las personas más longevas aseveran que «trabajada la salud, la vejez se vive bien» [Anónimo, 2 de junio de 2017], por tanto, son los impedimentos físicos de la edad los que condicionan el día a día y las inquietudes de estas personas. Este grupo de los más ancianos, tal y como afirman algunos de los contertulios, viven de la experiencia que comparten con orgullo con aquél que se preste a escucharlos. Trasladar las vivencias a los más jóvenes les supone una enorme satisfacción y se convierte en una de sus grandes aficiones. Son, además, los usuarios preferentes de los clubes de la tercera edad (Centro de Mayores Párroco Manuel Romero de San Nicolás y Centro de Mayores de La Isleta), que rehúsan en mayor medida los ancianos más jóvenes.

Al margen de los sentimientos y actitudes personales, en los barrios de estudio se aprecia un cierto compromiso comunitario frente al envejecimiento, con especial atención hacia aquellas personas con mayor dependencia y riesgo, como es el caso de los hogares en los que vive una persona mayor sola. La soledad es un sentimiento generalizado que aflige a muchos de estos ancianos, por lo que el acompañamiento se convierte en un servicio esencial. Son muchas las ocasiones donde la única visita que reciben son las del técnico socio-sanitario o de los voluntarios y vecinos comprometidos con su bienestar. Asimismo, en las visitas realizadas a algunos de estos hogares unipersonales, pudimos corroborar el impacto de la soledad y la satisfacción que les producía entablar diálogo y ser escuchados.

A tenor del trabajo cualitativo realizado, introducir estrategias comunitarias para combatir la soledad y favorecer un envejecimiento activo y una mayor vinculación social, son demandas muy solicitadas pero poco o mal resueltas. Algunos contertulios lamentan la falta de ingenio por parte de los centros de mayores para captar a personas mayores de 75 años, a la vez que critican a los poderes públicos y al olvido sistemático que soportan por parte de la Administración, por no garantizarles una vejez de calidad.

Pese a los contextos desfavorables del tejido urbano de ambos barrios, en especial el del Risco de San Nicolás, los arraigados sentimientos de pertenencia a los mismos, en los que muchos se definen orgullosos, como «una gran familia», facilitan una mejor calidad de vida a los ancianos. Un ejemplo de 
ello es el de las agradables tardes de paseo por calles como Guadiana en San Nicolás o pequeños rincones de La Isleta, lugares, en su concepción geográfica más humanista, que funcionan como grandes patios donde se desarrolla gran parte de la vida cotidiana de estos barrios.

\section{Conclusiones}

La investigación desarrollada en este artículo pone de manifiesto la riqueza epistemológica que entraña conjuntar las perspectivas geodemográfica y urbana en los estudios de vulnerabilidad socio-espacial. Especial importancia adquiere, en este caso, la combinación de los aspectos relativos al envejecimiento demográfico con los del medio ambiente urbano, entendiendo por tal los escenarios en los que se producen situaciones de exclusión y de fragilidad que afectan al bienestar de las personas mayores.

La metodología que se ha adoptado y que se ha revelado exitosa en esta investigación aúna técnicas cuantitativas y cualitativas de análisis. Desde un punto de vista cuantitativo, se han integrado en un sistema de información geográfica, a nivel de distintas escalas geográficas (parcela catastral, sección censal, barrio y municipio) datos demográficos, proporcionados por el Instituto Nacional de Estadística (Censo de Población y Padrón Continuo) y urbanos, también del INE (Censo de Viviendas), así como información catastral (Dirección General del Catastro). Con respecto a la investigación cualitativa, además de las entrevistas a técnicos en atención a personas mayores y a vecinos de los barrios objeto de estudio, se han revelado de gran interés los grupos de discusión, la herramienta más oportuna para el diagnóstico de la vulnerabilidad en el caso de estudio.

Por otra parte, la selección de las áreas de investigación ha intentado ofrecer un ejemplo de los barrios de la primera industrialización, barrios de cierta antigüedad y que carecen de valores patrimoniales reconocidos. La historiografía de la geografía urbana en España ha prestado escasa atención a la evolución que los caracteriza y aún menos a la relación que guarda dicha evolución con el ciclo de vida de sus vecinos, perspectiva que se ha adoptado en esta investigación para reconocer la disparidad de comportamientos en función de su capacidad para renovarse (La Isleta) o languidecer (San Nicolás).

El contexto de vulnerabilidad socio-espacial, producto del envejecimiento demográfico y urbano, es el punto de partida de la investigación desarrollada, pero el escenario resultante es consecuencia de las dinámicas urbanas que se manifiestan en dos realidades distintas. Por un lado, un barrio inmutable (San 
Nicolás), en el que la vulnerabilidad es extrema, a consecuencia de su marginalidad estructural. Y, por otra parte, La Isleta, que da síntomas de rejuvenecimiento gracias a los tímidos procesos de gentrificación y transformación.

Como consecuencia de ello, el estudio ha detectado situaciones de vulnerabilidad y exclusión socio-espaciales ante las que reacciona la propia comunidad de vecinos, revelándose de enorme importancia el sentimiento colectivo de identidad de barrio, es decir, el empoderamiento comunitario como respuesta a la fragilidad. En el caso de La Isleta, el Dr. Vicente Díaz, promotor de iniciativas de Arquitectura Colaborativa, respondía así a la pregunta de si existe preocupación por la gentrificación del barrio: «El sentimiento de identidad de los isleteros es su gran valor, pero algunos vecinos entendemos que la gentrificación y transformación del barrio puede ayudar a desatascar una situación de abandono y deterioro, y que ambas cuestiones pueden convertirse en fortalezas si se desarrollan en un buen contexto de convivencia».

Por su parte, la administración ha ido a remolque de las iniciativas comunitarias, facilitando en algunos casos soluciones que han contribuido a la regeneración urbana y manteniendo en el olvido a otros barrios, cuando las propuestas de intervención son más complejas. En cualquier caso, las dinámicas de los mercados del suelo y de la vivienda han sido definitivas, favoreciendo el dinamismo o la atonía económica, es decir, contribuyendo a la mayor vulnerabilidad de San Nicolás y a la menor de La Isleta, pese a su común origen como barrios obreros en proceso de envejecimiento.

\section{Bibliografía}

Abellán García, A., Fernández-Mayoralas, G., Rodríguez Rodríguez, V. y Rojo Pérez, F. (1990): "Envejecimiento de la población española y sus características sociosanitaria", Estudios Geográficos, 51 (199-200), pp. 241-257.

Alemán Hernández, R. (1998): "El origen de la vivienda obrera en la ciudad de Las Palmas (1847-1930)", en XIII Coloquio de Historia Canario Americana, Las Palmas de Gran Canaria, Casa de Colón, pp. 2911-2920.

Alguacil Gómez, J., Camacho Gutiérrez, J. y Hernández Aja, A. (2014): "La vulnerabilidad urbana en España. Identificación y evolución de los barrios vulnerables", Empiria. Revista de metodología de las ciencias sociales, 27, pp. 73-94.

AmiRisco (Amigos y amigas del Risco) (2017): Imágenes. https://www.google.es/sear $\mathrm{ch} ? \mathrm{q}=$ AmiRisco $+($ Amigos $+\mathrm{y}+$ amigas + del + Risco $) \& t b m=i s c h \&$ tbo $=u \&$ source $=u n i v$ $\& s a=X \& v e d=2 a h U K E w i \_s M C C 5 N b e A h X H a l A K H b y 3 C Z Y Q s A R 6 B A g G E A E \& b i w$ $=1920 \& b i h=969$

Andrews, G. J. y Phillips, D. R. (2005): Ageing and Place: Perspectives, Policy, Practice, London, Routledge, $252 \mathrm{pp}$. 
Batista, C., Hernández, T. e Inglott, E. (2000): "El Risco de San Nicolás: una historia olvidada y una marginación histórica", en XIV Coloquio de Historia Canario Americana, Las Palmas de Gran Canaria, Ediciones del Cabildo de Gran Canaria, pp. 1005-1018.

Bello Sánchez, W. (2013): "Vulnerabilidad socio-demográfica de las personas de la tercera edad", Cuadernos Geográficos, 52(1), pp. 153-177.

Butler, R. (ed.) (2006): The tourism area life cycle, 2 vols., Woodeaton, Oxford, Goodfellow Publishers Limited, $385+352$ pp.

Calderón Calderón, B. (2001): "Un espacio creado y transformado por el permanente conflicto entre centro y periferia: una hipótesis-más para interpretar el modelo de crecimiento urbano en España", en F. Manero (coord.), Homenaje al Dr. D. Jesús García Fernández, Valladolid, Universidad de Valladolid, pp. 589-598.

Capel Sáez, H. (1975): Capitalismo y morfología urbana en España, Barcelona, Los Libros de la Frontera, 142 pp.

CIES [Centro de Investigación Económica y Social de la Caja Insular de Ahorros] (1970): Acotaciones a la ciencia urbana y su metodología. Aplicación al área metropolitana de Las Palmas, Boletín n. ${ }^{\circ}$, Las Palmas, Caja Insular de Ahorros.

Conoce La Isleta (2014): Imágenes. https://www.google.es/search?q=conoce+la+isleta+ $\mathrm{im} \% \mathrm{C} 3 \%$ Algenes\&tbm $=$ isch \& $\mathrm{tbo}=\mathrm{u} \&$ source $=$ univ\&sa $=\mathrm{X} \& \mathrm{ved}=2 \mathrm{ahUKEwi} 2 \mathrm{xYm}$ G5dbeAhXRLVAKHXmvCSwQsAR6BAgBEAE\&biw=1920\&bih=969

Domínguez Mujica, J. y Gironés Montesdeoca, N. (2001): "Un estudio de geografía histórica: la génesis del barrio de La Isleta", El Museo Canario, 56, pp. 233-259.

Fadda, G. y Cortés, A. (2009): "Hábitat y adulto mayor: el caso de Valparaíso", Revista INVI, 24(66), pp. 89-113.

FEDAC. Fundación para la Etnografía y el Desarrollo de la Artesanía Canaria (2017): Archivo de fotografía histórica de Canarias. http://www.fotosantiguascanarias.org/

Golant, S. M. (2015): Aging in the Right Place, Baltimore, Health Professions Press, $406 \mathrm{pp}$.

Hernández Aja, A., Matesanz Parellada, Á., García Madruga, C., Alguacil Gómez, J., Camacho Gutiérrez, J. y Fernández Ramírez, C. (2015): Atlas de Barrios Vulnerables de España: 12 Ciudades 1991/2001/2006, Madrid, Instituto Juan de Herrera, 345 pp.

Lawton, M. P. (1975): Planning and managing housing for the elderly, New York, Wiley, 336 pp.

Martínez Zimmermann, M. L. (2011): Los proyectos de vivienda de promoción oficial para la población civil en la ciudad de Las Palmas de Gran Canaria, tesis doctoral, Universidad de Las Palmas de Gran Canaria, 649 pp., http://hdl.handle. net/10553/17168 (Fecha de consulta: 28/9/2017).

Méndez, R., Abad, L. D. y Echaves, C. (2015): Atlas de la crisis. Impactos socioeconómicos y territorios vulnerables en España, Valencia, Tirant Lo Blanc, 301 pp.

Narváez Montoya O. (2011): "Urbanismo Gerontológico: Envejecimiento demográfico y equipamiento urbano en Aguascalientes", Investigación y Ciencia de la Universidad Autónoma de Aguascalientes, 19 (51), pp. 16-24. 
Peet, R. y Rowles, G. (1974): "Geographical Aspects of Aging”, Geographical Review, 56, pp. 445-447.

Puga González, M. D. y Abellán García, A. (2006): "Las escalas territoriales del envejecimiento", SEMATA, 18, pp. 121-141.

Quintana Andrés, P. (2000): "La génesis de un espacio social desigual: los Riscos de Las Palmas durante el Antiguo Régimen", en XIV Coloquio de Historia Canario Americana, Las Palmas de Gran Canaria, Ediciones del Cabildo de Gran Canaria, pp. 990-1004.

Quirós Linares, F. (1991): Las ciudades españolas en el siglo XIX. Vistas de las ciudades españolas de Alfred Guesdon. Planos de Francisco de Coello, Valladolid, Editorial Ámbito, 430 pp.

Rojo, F., Fernández-Mayoralas, G. y Pozo, E. (2000): "Envejecer en casa: los predictores de la satisfacción con la casa, el barrio y el vecindario como componentes de la calidad de vida de los mayores en Madrid", Revista Multidisciplinar de Gerontología 10(4), pp. 222-233.

Rowles, G. D. y Chaudhury, H. (eds.) (2005): Home and identity in late life: International perspectives, New York, Springer Publishing Company, 399 pp.

Rowles, G. D. y Bernard, M. A. (eds.) (2013): Environmental gerontology: Making meaningful places in old age, New York, Springer Publishing Company, 320 pp.

Sánchez-González, D. (2007): "Envejecimiento demográfico urbano y sus repercusiones socioespaciales en México. Retos de la planeación gerontológica", Revista de Geografía Norte Grande, 38, pp. 45-61.

Sánchez-González, D. (2009): "Geografía del envejecimiento vulnerable y su contexto ambiental en la ciudad de Granada: Discapacidad, dependencia y exclusión social”, Cuadernos Geográficos, 45, pp. 107-135.

Sánchez-González, D. (2015): “Ambiente físico-social y envejecimiento de la población desde la Gerontología Ambiental y Geografía. Implicaciones socioespaciales en América Latina", Revista de Geografía Norte Grande, 60, pp. 97-114.

Sánchez-González, D. y Egea-Jiménez, C. (2011): "Enfoque de vulnerabilidad social para investigar las desventajas socioambientales. Su aplicación en el estudio de los adultos mayores", Papeles de Población, 17(69), pp. 151-185.

Scharf, T. y Keating, N. C. (2012): From exclusion to inclusion in old age: A global challenge, Policy Press, 176 pp.

Skinner, M. W., Andrews, G. J. y Cutchin, M. P. (2017): Geographical gerontology: perspectives, concept and approaches, New York, Routledge.

Smith, E. A. (2009): Ageing in Urban Neighborhoods: Place Attachment and Social Exclusion, Bristol, The Policy Press-University of Bristol, 248 pp.

Terán, F. de (1982): Planeamiento urbano en la España contemporánea (1900-1980), Madrid, Alianza.

Torres Balbás, L., Vera, L. C., Chueca Goitia, F. y Lasarte, P. B. (1954): Resumen histórico del urbanismo en España, Madrid, Instituto de Estudios de Administración Local, 289 pp. 
Torres Gutiérrez, F. J. y García Herrera, L. M. (2011): "Metodologías para el análisis de la desigualdad urbana y la exclusión social. Aplicación al caso de la ciudad de Sevilla y sus barrios", Ería, 84-85, pp. 103-108.

Valenzuela, M. (ed.) (2013): Las ciudades españolas en la encrucijada. Entre el "boom inmobiliario" y la crisis económica, Madrid, Real Sociedad Geográfica, 584 pp.

Vázquez-Barquero, A. (1999): "Dinámica productiva y desarrollo urbano: La respuesta de la ciudad de Vitoria (País Vasco) a los desafíos de la globalización", EURE, 25(74), pp. 19-33.

Vilá Valentí, J. y Capel Sáez, H. (1970): Campo y ciudad en la geografía española, Barcelona, Salvat, 192 pp.

Wahl, H-W., Iwarsson, S. y Oswald, F. (2012): "Aging well and the environment: toward an integrative model and research agenda for the future", Gerontologist, 52(3), pp. 306-316.

Windley, P. G. (1972): Environmental dispositions of older people, Doctoral dissertation, University of Michigan, $135 \mathrm{pp}$.

Fecha de recepción: 30 de octubre de 2017.

Fecha de aceptación: 16 de octubre de 2018. 